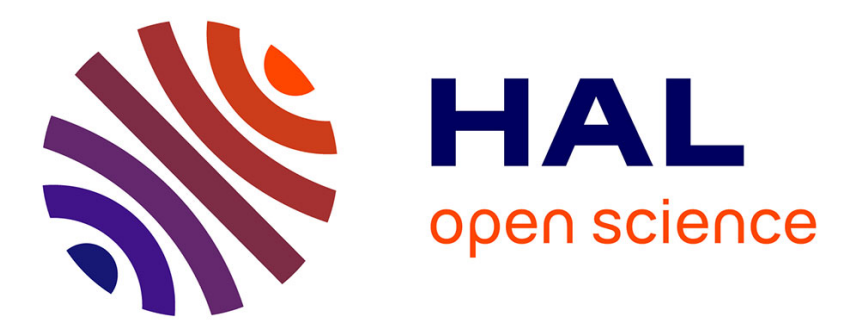

\title{
Choice, sorting and ranking in aerial conflict management
}

David Annebicque, Igor Crevits, Patrick Millot, Serge Debernard

\section{To cite this version:}

David Annebicque, Igor Crevits, Patrick Millot, Serge Debernard. Choice, sorting and ranking in aerial conflict management. IFAC Proceedings Volumes, 2010, 43 (13), pp.31-36. 10.3182/201008314-FR-2021.00007 . hal-02112910

\section{HAL Id: hal-02112910 https://hal.science/hal-02112910}

Submitted on 27 Apr 2019

HAL is a multi-disciplinary open access archive for the deposit and dissemination of scientific research documents, whether they are published or not. The documents may come from teaching and research institutions in France or abroad, or from public or private research centers.
L'archive ouverte pluridisciplinaire HAL, est destinée au dépôt et à la diffusion de documents scientifiques de niveau recherche, publiés ou non, émanant des établissements d'enseignement et de recherche français ou étrangers, des laboratoires publics ou privés. 


\title{
Choice, sorting and ranking in aerial conflict management
}

\author{
D. Annebicque, I. Crévits, P. Millot, S. Debernard \\ Univ Lille Nord de France, F-59000 Lille, France ; UVHC, LAMIH, F-59313 Valenciennes, France ; \\ CNRS, FRE 3304, F-59313 Valenciennes, France. \\ (e-mail: \{david.annebicque, igor.crevits, patrick.millot, serge.debernard\}@univ-valenciennes.fr).
}

\begin{abstract}
In the Air Traffic control, many decisions must be taken, quickly. Due to the increase of traffic, these decisions are more and more numerous. It is possible to propose some assistance tools to air traffic controllers in order to help them to make decisions. For that purpose we need to understand how the controllers make these decisions. This paper proposes a knowledge acquisition approach composed of three steps: an analysis of the decision-making process, a multiple criteria methodology, and interviews in order to obtain information, and to develop models. The last part of this paper presents the results we expect to obtain with appropriate interviews and analyse.
\end{abstract}

Keywords: Decision Making Process, Multiple Criteria Methodology, Air Traffic Control, interviews analysis, choice, sorting and ranking problems, decision support tools.

\section{Introduction}

Making a decision is a fundamental task for Human. In professional contexts it providing by assistance tools, to the operators needs, to understand how the operators decide and then to study their decision-making process.

Our application field is the Air Traffic Control (ATC), and the human operators, are the air traffic controllers. This context is very well adapted to decision support tools especially when the traffic increases. And this cannot be realized without making a precise study on the decision making process of air traffic controllers.

The LAMIH has been working with the $\mathrm{DGAC}^{1}$ for many years in this objective. The laboratory has developed several platforms with a common philosophy which is to keep the operator at the centre of the loop, and thus to develop cooperative systems. Former studies were oriented toward the concept of Human-Machine Cooperation. Now we complete our platform with the implementation of dedicated assistance tools that needs to understand how the Planning Controller (PC) manage the traffic they have in charge in their own geographical sector, but also the traffic around them and the other controllers.

This paper begins with a presentation of ATC and especially the problems drawn by an increase of traffic. The second part presents the project AMANDA (Automated machine MAN Delegation of Action), and its evolutions. The third part presents the approach which is put in place to understand and analyse the activities of the PC. Finally, the last part presents the results of the interviews analysis, realised with

\footnotetext{
${ }^{1}$ DGAC is the French acronym for general direction of the civil aviation
}

professional air traffic controllers of the $\mathrm{CRNA}^{2}$-Est in Reims.

\section{Management of en-route Air Traffic}

\subsection{Organisation of Air Traffic Control}

ATC is organized in 3 layers: "Airport control", "Approach and terminal control" and "en-route control". The third layer manages flights passing through in the airspace between the departure airport's control and the destination airport's approach control. The objective of en-route ATC is to guarantee the safety of the aircraft and their passengers. For that purpose, the controllers impose a minimum separation distance between the aircraft (5NM in the horizontal plane and $1000 \mathrm{ft}$. in the vertical plane), while also insuring that they respect the economic constraints related to time and fuel consumption. When two aircraft do not respect these minimum distances, they provide a "conflict".

Airspace is divided into geographical sectors which make the air traffic management and supervision easier. Two controllers are responsible for constantly supervising a geographical sector: a Planning Controller (PC) and an Executive Controller (EC). PCs coordinate the movement of the aircraft between their sector and the adjacent sectors by negotiating the aircraft entrance and exit conditions. In that way, PCs also regulate the workload of the ECs. ECs are responsible for the traffic supervision, in their sector, making sure that the aircraft respect the flight plans and maintain the safety distances. If an EC detects a possible conflict he/she do all possible to restore the safety distances and avoid the conflict. Generally, it is necessary to reroute one of the aircraft, and then to put this aircraft back on its original

\footnotetext{
${ }^{2}$ CRNA is the French acronym for regional centre of air navigation
} 
trajectory when the separation has been guaranteed. This type of action is called conflict resolution.

\subsection{Motivation of the study}

During the 25 years from 1977 to 2002, the traffic crossing through French airspace has increased of $250 \%$. The air traffic is today over 2,900,000 aircraft per year ${ }^{3}$, which means an average of 8,000 aircraft per day. For instance, in a geographical sector around Bordeaux, the controllers must manage 20 to 25 aircraft per hour, which is a reasonable workload for the controllers. But DGAC foresees the traffic density will be multiplied by 3 in the next 20 years. Therefore, the controllers will have more and more difficulty to manage this increase with the present assistance tools (radar view, strips and telephone) with an increasing risk of overload at certain moments in the day and then a lake of safety.

Several solution heave been proposed. But reducing the sectors size is now impossible because conflict resolution requires a sufficient geographical area for allowing aircraft to manoeuvre successfully. Moreover a total automation of ATC is impossible; in addition to psychological consequences that this would have on the passengers, such a level of automation would imply changing the entire instrumentation of the aircraft, which is not economically conceivable. Currently, to avoid overloading the controllers, different solutions have been adopted: for example, flights trajectories are planned, airport departure are now regulated, and the coordination between sectors has been enhanced. These solutions allow the complexity of air conflicts to be reduced, and even help to avoid such conflicts all together.

The question is approached in terms of assistance to the controllers. Assistance tools to improve the regulation of the workload of controllers are proposed. But they must perfectly match with the control tasks and the controller work (as a pair, as individually), for producing a beneficial effect.

\section{Project AMANDA}

The AMANDA project (Automation MAN-machine Delegation of Action, Debernard et al., 2002; Guiost et al., 2004), as well as other projects developed in our laboratory (Crévits et al., 1993, Debernard, Vanderhaegen and Millot, 1992), took place into this context. These projects all had the same philosophy, to keep the human operator in the control loop. These projects do not seek the fully automation of the ATC management, which would result in loss of operator competence, as well as a loss of situation awareness (SA) (Endsley, 1996; Endsley and Kaber, 1999).

\subsection{AMANDA V2}

AMANDA V2 gathers several tools which assist the controllers (PC and EC) in one sector, by providing a task

\footnotetext{
${ }^{3}$ The 2008 data appears in the DGAC annual report, posted on their website: www.dgac.fr
}

delegation between these tools and the Human controllers (Debernard et al., 2002). This delegation is based on a shared representation of the airspace and of the conflicts, thus maintaining common situation awareness.

\section{- Decision Support System}

STAR is the French acronym for "tactical system for conflict solving assistance" (Debernard et al., 2002). It integrates a trajectory calculation and an assistance tool for air conflict resolution. STAR works in cooperation with the controller. The controller detects a conflict and then may (or not) use STAR for resolving this conflict. (STAR does not detect conflicts.) To do this, the controller indicates a strategy, called a directive that he/she wants to apply to resolve the conflict. For example, a directive could be "AFR1542 PASS_BEHIND KLM1080", where AFR1542 and KLM1080 are two flight numbers. STAR takes this directive into account in order to propose a solution. To do so, STAR calculates a whole set of new trajectories that respect the directive without, of course, creating new conflicts. After making a choice based on specific criteria (e.g., the number of deviations), STAR then proposes ONE trajectory to the human controller. The controller then examines the solution proposed by STAR. If the solution is satisfactory, he/she can delegate or not the execution of the solution. In the first case, STAR is responsible for communicating the instructions (e.g., change in heading or flight level) directly to the aircraft. Thus the controller does not execute the solution and does not communicate with the pilots. If the solution is not satisfactory, the controller resolves the conflict by choosing a heading and by sending this heading to the pilot of the aircraft, like he/she would do without tool.

\section{- The Common Work Space}

The Common Work Space (CWS) is a key concept introduced in AMANDA (Bentley et al., 1992; PacauxLemoine and Debernard, 2002). CWS allows information to be shared between all agents, both human (i.e., controllers) and artificial (i.e., STAR). Each agent can introduce new information into the CWS according to its ability (knowhow) and its role (authority) in the process. All the agents can consider this information in order to carry out their tasks or control the tasks of the other agents. The CWS allows a common Situation Awareness (SA) to be maintained between the two human controllers (PC and EC), who can share their representation of the problems to be supervised and/or resolved (e.g., air conflict or loss of separation). The controllers are responsible for maintaining their CWS up-todate in order to preserve a coherent "picture" of the situation and the airspace, as well as to inform the platform, especially STAR, of the conflicts that they detect.

The platform was tested with professional controllers (Guiost, Debernard, 2007). The controllers appreciated the CWS, but disagree with the choice of aircraft in clusters: in fact AMANDA has added some inappropriate aircraft, and STAR has proposed sometimes, some trajectories inconsistent with the practices of controllers. These trajectories lead to a more complex analysis. 


\subsection{AMANDA V3}

With AMANDA V2 solving the conflict deals with only the aircraft within the sector, this limiting the possibilities for predicting the flight trajectory. The objectives of the Amanda V3 project are to integrate the adjacent sectors into the system and to improve the trajectory calculation tool, STAR (Annebicque et al., 2008a). Integrating the adjacent sectors requires extending CWS principles to the cooperation among the Planning Controllers of the adjacent sectors. This new CWS will:

- Facilitate negotiation between sectors by allowing a quick visualization of the flight concerned by negotiations, thus reducing the workload and the time needed to negotiate, as well as the risk of ambiguity.

- Facilitate sharing between the sectors, for example, about changes in aircraft trajectories, which should help to reduce the uncertainty about the positions and entry conditions of flights in a given sector.

STAR's module of calculation seems to be too "precise" for the controllers knowing the important uncertainty which can exist due to weather forecast for instance. In fact, the calculation module uses mathematical methods to provide the new trajectory in response to the controller's directive, thus provides "perfect" trajectories. However, it does not take into consideration the additional factors introduced by controllers to enhance their confidence in the trajectories, such as a safety margin above the minimum separation distance $(15 \mathrm{NM})$, a comfortable $\left(<30^{\circ}\right)$ deviation rate (heading) or the anticipation of unstable aircraft.

\subsection{Approach}

Our study is divided into three phases, as outlined by Annebicque et al. (2008b). The first phase focuses on analyzing and structuring the decision-making process. First, it is necessary to analyze the PC decisions with respect to the coordination with the adjacent sectors. These decisions must be coherent with both the PC's strategic/tactical decisions and the EC's operational decisions for the internal management of their sector. This phase will focus on describing a coherent decision-making process.

The second phase is methodological, aiming to structuring each decision in the decision-making process. A general methodological framework must be sought to promote the consistency of each decision in relation to the entire decisionmaking process. Several participants help make the decision, each one contribution being based on his/her own value system, so this methodological framework must also structure these exchanges between the various participants. It should also help to identify, represent and, finally, influence the different participant value systems.

The third phase is the modelling phase, a classical one in the field of decision-support. The third phase aims to identifying and structuring the elements that allow tools to be designed in order to aid the decision-makers. Consequently, we need to collect the decision elements manipulated by the controllers. We can note that the controllers are not the only people who possess these elements. The Air Navigation staffs responsible for controller training also has some of these elements, as do the AMANDA tool designers working from a engineering approach. However, controllers are the only ones who, through the results that they produce, can validate the model.

\section{Structuring the problem}

\subsection{Decision-making process}

Air Traffic Control decisions are continuously. At the operational level, they consist of changing the aircraft trajectory by adjusting the aircraft flight parameters in order to resolve a conflict situation. Working in cooperation with STAR, the ECs are responsible for this operational level (Figure 1, level 3).

At the tactical level, the ECs stay at a central position (Figure 1, level 2), but they work in partnership with the PCs, through the CWS which facilitate the cooperation between them. Since they receive the information beforehand, the PCs prepare the operational decisions for the ECs. The PCs may have already identified a conflict situation and will inform the $\mathrm{EC}$ at the right time. When informed, the ECs integrate this new situation into their management of the air traffic, using the details for the PC's pre-prepared decisions in order to be able to make them operational.

At the strategic level (Fig. 1, level 1), the PCs again receive first the available information about flights that will pass in the sector. The PCs have a strategic vision of the potential conflict situations. The CWS allows the PCs to explain and share this vision with the ECs, who then can exploit this information to manage the sector. In the context of strategic management, a PC may contact an adjacent sector in order to, for example, change aircraft flight entry levels to avoid a conflict in his/her sector, or preventing an EC work overload. The CWS therefore quite naturally allows the PCs to manage the various sectors strategically. The synthetic vision of the CWS is coherent with the tactical management dealt with at the previous level.

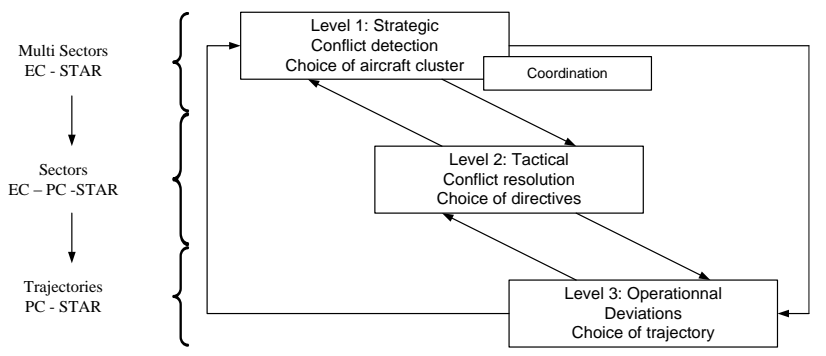

Fig. 1. Synthesis diagram of three levels of the study, and the links between them.

These three levels are studied as independently as possible in order to obtain accurate results focused on a specific problem, providing the opportunity to go into detail for each level. Nevertheless, the levels are interconnected. In fact, it would be somewhat surprising to choose a trajectory without having problems related to this choice. Quite logically, 
strategic decisions (level 1) appear to influence tactical decisions (level 2), and vice versa, and tactical decisions (level 2) appear to influence operational decisions (level 3), and vice versa. Quick operational decisions are also possible, and thus correspond to a direct link between a strategic decision (level 1) and operational tasks (level 3).

\subsection{Multiple criteria methodology.}

It would be quite unrealistic to summarize in a single goalsafety, cost or time - the actions taken by the controllers because ATC is by nature multi-criteria. The controllers' job is to search for a compromise between the various values systems. This is typically called managing aircraft flows: by acting on the air traffic, the controllers try to insure optimal safety, while at the same time trying to reduce delays and fuel consumption. The controllers' actions are the final phase of ATC management and, as such, are the result of previouslymade controller decisions. Given this context, it seems appropriate to approach the design of a decision-support system from the point of view of Multi-Criteria DecisionMaking (MCDM).

The MCDM methodology (Roy, 1996) places the concept of decisions in a decision-making process in which several participants play a role determined by their own interests. In MCDM, the decision-making problem itself is studied. MCDM suggests 4 fundamental problems: choice (choose the best alternative), sorting (sort the alternatives into non-ranked homogenous groups), ranking (rank the alternatives from best to worst), and description (describe the problem into detail).

MCDM has four levels (Fig. 2). At the first level, the potential actions to solve the fundamental problems are clearly defined. These potential actions include all the possibilities (real or fictitious) on which the decision will be made. At the second level, the criteria that characterize the potential actions are identified. At the third level, the preferences (i.e., a set of rules through which the potential actions are linked across the criteria) are determined. At the fourth level, recommendations are established. This last level is the methodology's operational level, where the recommendations are implemented.

Studying the three levels independently will lead to three MCDM processes: defining three fundamental problems, identifying three criteria families, determining three sets of preferences, and establishing three recommendations. However, the recommendations established at level 4 will be more general. These three studies will produce a cooperative system, contained in a single platform. This platform will include the different decisions and different tools responding to and corresponding to each of the recommendations, grouped within a single environment, the CWS.

Human-Machine Cooperation (HMC) is the thread unifying this system. HMC takes place especially at level 4 of the MCDM methodology (i.e., recommendations). The main objective of HMC is to understand the steps that the controllers use in their cooperation with the adjacent sectors (i.e., how they cooperate).

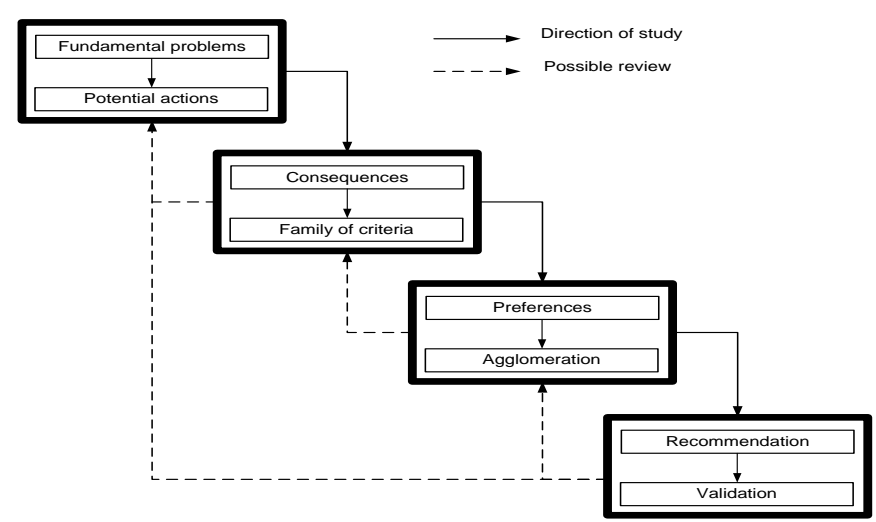

Fig. 2. Synthesis diagram of the Multiple criteria Decision Making methodology (MCDM).

\subsection{Knowledge Acquisition, Interviews}

In order to create the models and recommend some decision support tools, it is first necessary to understand how the controllers work and the data that they manipulate. To attend this objective, an interview protocol, as well as a review process, was proposed to the professional ATC controllers.

Three 2-hour-long interviews were conducted. The interviews were based on a real situation, extracted from the previous experiment for AMANDA V2 and presented to the controllers. The advantage of using situations extracted from a previous experiment is double. First, it provides results, data, choices and decisions made by controllers during the previous experiments and thus the scenarios presented tend to be more realistic. Secondly, proposing a situation based on another sector allows us to obtain more precise and more detailed responses that are less "automated" than they would be for the scenarios situated in their usual work sector. Each interview had a defined objective:

- $\quad 1^{\text {st }}$ interview: to discover, comment and analyze the situation.

- $\quad 2^{\text {nd }}$ interview: to return to the analysis of the situation, with more precise questions based on the first interview; to explain the "jargon" in order to avoid all ambiguity.

- $\quad 3^{\text {rd }}$ interview: to discuss the fundamental problem of coordination, the possible scenarios, the different ways of doing the controller's job, and the exchange of data, for example.

Each interview was reviewed with transcriptions of the discussion and then validated by the controllers. We focus only on the conflict resolution aspect in this paper (interview 1 and 2).

\section{A first decision model}

\subsection{Analysis principles}

The interviews allowed the experimental results for AMANDA V2 to be compared to the practices of professional ATC controllers. Two types of results were available. The analysis of the interview content provided a 
first type of results about the foundations of the ATC profession, which is useful information when designing decision support tools. The second type of results identifies the nature of the decisions made by the controllers. From this analysis it is possible to determine which kind of problematic (as meant in MCDM) is applied and to extract some criteria for each level.

\subsection{Results for level 1: conflict detection - Choice}

The situation submitted to the controllers for judgment presented different aircraft clusters. A cluster contains the aircraft to be taken into account in order to resolve the conflict. A possible conflict appears when two aircraft are not separated by the minimal distance of separation. A cluster (as meant in AMANDA V2) contains the two aircraft involved in the conflict and another aircraft, called "restrictive aircraft", which can disturb the resolution of the conflict. During the interviews, we presented the controllers with 4 clusters: one cluster with only the two aircraft involved in the conflict and three clusters, each with a different restrictive aircraft, in order to evaluate the impact of restrictive aircraft on the resolution. The status of the global situation was also presented via the strips (i.e., a paper tape that contains all the flight data) and the radar view.

Interviews analysis shows that controllers are confronted to a problematic of choice. The objective is to choose which aircraft to take into account in the cluster. This choice is relatively simple because they only consider the two aircraft directly in conflict; this is the main criterion of choice. If necessary, they propose an increased surveillance on one aircraft that could potentially disrupt the conflict.

Controllers have actually two levels of conflict detection. The first level, generally directed by the PC, is when the PC receives the strip. He/she compares the estimated time of passage on each beacon, and then determines if an aircraft is potentially in conflict with others aircraft already present in the sector. In fact at this stage, PC eliminates aircraft which are not in conflict. The second level, usually made by the EC, is on the radar view and consists to a more precise detection.

The usual notions of conflict and surveillance are sufficient to structure their decisions. However, a support confirming their judgment could be supplied. In addition, this result indicates that the controllers never manipulate simultaneously several different clusters during the conflict detection phase. They focus only on one possibility, which represents the situation the most simply, (i.e., in the same way that it is presented on the strips); simplicity of the cluster can be another criterion for the choice. They don't compare several possibilities and then pick the best alternative. Thus, decisions in this conflict detection phase seem to be based on the problem description (in meaning of Roy).

\subsection{Results for Level 2: conflict resolution - Sorting}

In addition to presenting the situation via the strips and the radar views, we asked the controllers to analyse six types of resolution strategies, called directives. Three of the six directives required the controllers to act on one of the two conflicting aircraft in order to resolve the conflict from inside the cluster. One directive required action on an aircraft outside the conflict. One directive intentionally presented a hazardous configuration, MCDM suggest to propose fictitious situations. The sixth directive presented an efficient resolution strategy, but one was marginal in terms of the current practices.

The analysis shows that controllers try to apply three main criteria when they resolve a conflict: accentuate the natural tendencies of aircraft, make an "elegant resolution", and save energy and resources.

The natural tendency is when one of the two aircraft would naturally cross behind the second, without any action being taken on the aircraft. In this respect the controller will slightly increase the deviation of the second aircraft at the point of conflict in order to increase the separation distance between two aircraft on this point. Respecting the natural tendencies allows to make "elegant" solutions, i.e. which respect the planned trajectories, which do not disrupt other, traffic, and preserves the comfort of passengers.

The other aspect in the choice of a directive is to save energy. Controllers are still trying to choose the least-cost strategies in order to act quickly, without using too many resources, and thus keep resources to handle any unexpected events.

However, the global situation can make this "elegant" solution inappropriate or impossible. It is still possible to resolve the conflict from the inside by acting on the first aircraft at the point of conflict, although the deviation will necessarily be larger. If needed, secondary actions can be carried out on other aircraft, in order to keep the required resolution space.

When an elegant solution cannot be carried out, the controllers make their choices according to this energy cost. The less costly action is the preferred choice of the controllers even if the solution is less elegant.

There are two kinds of decisions made on this level. At the most global level, the choice is usually between a natural resolution and a non-natural resolution, with the decision being a choice between two categories. Then, once the resolution category has been chosen, the variants of the natural or non-natural resolution are considered. The problematic consist in sorting the possibilities into two groups: resolution and protection.

\subsection{Results for Level 3: The deviation - Ranking}

A trajectory represents the future route of the aircraft, the result of the deviation and the return to the original route. Only one trajectory was submitted to the controllers for evaluation, with the goal of obtaining a critique, as well as alternative propositions.

In this level, the goal, and one criterion, is apparently to deviate the aircraft slightly $\left(5^{\circ}\right.$ to $\left.10^{\circ}\right)$ as soon as possible, 
which results in an elegant resolution. The controllers provided precisions about the rules governing the relationship between the value of the heading and the distance from the point of conflict. The trajectory is a result of these rules, and not an explicit search for the best value that will insure aircraft separation. The deviation is a result of the time available to resolve the conflict and the controller's workload.

The controllers didn't really mention the return to the original route after a deviation, which is not considered as a part of conflict management, but as the result of the surveillance.

Like the conflict detection level, the controllers don't explicitly compare alternative deviations. The rules provide a ranked set of alternatives, according to the decreasing distance from the point of conflict. The decision is made based on the ranking of the alternatives; the one that allows the directive to be applied the earliest is chosen.

\section{CONCLUSION}

In this paper an approach is presented, to realize a knowledge acquisition, in order to realize models and tools able to assist the air traffic controller to assume the increase of traffic. The goal of this knowledge acquisition is to develop some model of the controllers' decision making process. The last part of this paper shows the result of an analysis of interviews, and the information that it is possible to obtain, like problematic and criteria. These results offer a real and good idea of the controllers' way of doing i.e.: data they manipulate, the decisions they take, the choice they make. Now the next step is to modelling these results in order to propose model of the air traffic controller, and then develop tools.

\section{ACKNOLEDGMENTS}

We would like to thank all the ATC personnel, who through their availability and collaboration made it possible to develop and evaluate the various platforms. We also want to thank the DGAC/SDER/DTI. This research was also supported by International Campus on Safety and Intermodality in Transportation, the Nord/Pas-de-Calais Region, the European Community, the Regional Delegation for Research and Technology, the French Ministry of Higher Education and Research, and the National Centre for Scientific Research. The authors gratefully acknowledge the support of these institutions.

\section{REFERENCES}

Annebicque, D., Debernard, S., Poulain, T. and Crévits, I. (2008a) 'AMANDA V3: Toward a Common Work Space between air Traffic Controllers'. In ACHI 08. February, 2008. Sainte Luce.

Annebicque, D., Crévits, I., Poulain, T. and Debernard, S. (2008b) 'Knowledge acquisition for the creation of assistance tools to the air traffic control'. In: Zaraté, P., Belaud, J.P., Camilleri, G. and Ravat, F (ed.), Collaborative Decision Making: Perspective and Challenges, IOS Press, CDM'2008 (pp.321332). Toulouse, France.

Bentley, R., Rodden, T., Sawyer, P. and Sommerville, I. (1992) 'An architecture for tailoring cooperative multi-user displays'. In Conference proceedings of $4^{\text {th }}$ Computer - supported cooperative work (pp.187-194). Toronto, Canada.
Crévits, I., Debernard, S., Vanderhaegen, F. and Millot, P. (1993) 'Multi level cooperation in air traffic control'. In $4^{\text {th }}$ International Conference on Human-Machine Interaction and Artificial Intelligence in Aerospace. September, 1993. Toulouse, France.

Debernard, S., Guiost, B., Poulain, T., Crévits, I., Annebicque, D. and Millot P. (2009) 'Integrating Human Factors in the Design of Intelligent Systems: an example in Air Traffic Control', International Journal of Intelligent Systems Technologies and Applications. Vol. 7, No. 2, pp. 205-226.

Debernard, S., Cathelain, S., Crévits, I. and Poulain, P (2002) 'AMANDA Project: Delegation of tasks in the air-traffic control domain'. Cooperative Systems design, IOS PRESS (pp.173-190). January, 2002.

Debernard, S., Vanderhaegen, F. and Millot, P. (1992) 'An experimental investigation of dynamic task allocation between air traffic controller and AI system'. In 5th IFAC/IFIP/IFORS/IEA Symposium on Analysis, Design and Evaluation of Man-Machine Systems. June 9-11, 1992. The Hague, The Netherlands.

Endsley, M.R. (1996) 'Automation and situation awareness'. Automation and human performance: Theory and applications (pp. 163-181), Mahwah, NJ: Lawrence Erlbaum Associates

Endsley, M.R. and Kaber, D.B. (1999) 'Level of automation, effects on performance', situation awareness and workload in a dynamic control task. Ergonomics, Vol. 42, No. 3, pp. 462-492.

Guiost, B., Debernard, S., Poulain, T. and Millot P. (2004) 'Supporting Air-Traffic Controllers By Delegating Tasks'. In IEEE-SMC 2004 (pp 164-169). September, 2004. The Hague, The Netherlands.

Guiost, B. and Debernard, S. (2007) 'Common Work Space or How to Support Cooperative Activities Between Human Operators and Machine: Application to Air Traffic Control'. In 12th International Conference on Human-Computer Interaction. Springer. July, 2007. Beijing, P.R. China.

Hoc, J-M. and Debernard, S. (2002) 'Respective demands of task and function allocation on human-machine co-operation design : a psychological approach'. Connection Science, Taylor \& Francis, Vol. 14, No. 4, pp. 283-295.

Millot, P. and Debernard, S. (2007) 'An Attempt for conceptual framework for Human-Machine Cooperation'. In IFAC/IFIP/IFORS/IEA Conference Analysis Design and Evaluation of Human Machine Systems, September, 2007. Seoul, Korea.

Pacaux-Lemoine, M.-P. and Debernard, S. (2002) 'A common work space to support the Air Traffic Control', Control Engineering Practice, A journal of IFAC, Vol. 10, pp 571-576.

Pacaux-Lemoine, M-P., Debernard, S., Crévits, I. and Millot, P. (1996) 'Cooperation between humans and machines: first results of an experimentation of a multi-level cooperative organisation in air traffic control'. Computer Supported Cooperative Work, Vol. 5, pp. 299-321.

Roy, B. (1996) Multicriteria Methodology for Decision Aiding, Kluwer. London.

Vanderhaegen, F., Crévits, I., Debernard, S. and Millot P. (1994) 'Human-machine cooperation : toward an activity regulation assistance for different air traffic control levels'. International Journal on Human-Computer Interaction, Vol. 6, pp. 65-104. 